\title{
Development and Validation of Technology Enhanced Learning Framework Driven by Flipped Methodology Learning Environment
}

\author{
KIFAYAT ULLAH*, SYED TASWEER HUSSAIN SHAH*, SYED MUHAMMAD ALI*, AND ALVEENA KHAN**
}

RECEIVED ON 31.12.2018 ACCEPTED ON 19.02.2019

\begin{abstract}
Technology has contributed in every aspect of society. Academics is not an exception. The management of educational technology has come up with exceptional results in the new paradigm of learning environment. In recent years, flipped learning approach has gained much popularity and has been more widely accepted and adopted as a driving force for enabling active learning. This paper defines the formulation of novel framework, inspired by flipped learning approach, leading to effective learning environment. It also describes a novel extension of student-centered learning by integrating educational technology, technology enhanced learning strategy, student questions generation and instant response system into the higher education. It also examines the impact of this extension on student learning engagement, motivation, attitude, and calculating the impact of acceptance for unconventional education on the overall system.
\end{abstract}

The result indicated that effective learning environment has a significant positive effect on learning motivation and engagement. The result showed that the constructs of education technology, technology enhanced learning strategy, students question generation and instance response system in the presence of "impact of acceptance for unconventional education" has an effect on formulating effective learning environment. Research recommendations are given on the basis of results of the study.

Key Words: Technology Enhanced Learning, Flipped Learning, Education Technology, Instant Response System, Student Question Generation, Information \& Communication Technology.

\section{INTRODUCTION}

$\mathrm{F}$ lipped classroom a widespread word, new idea and an alternative pedagogical approach in which teacher- centered learning instruction is shifted to student centered approach. Flipped classroom has reversed the conventional classroom learning environment. Therefore, it has newly gained much popularity, acceptance and has become commonly implemented in most of the educational institutions. The flipped classroom or student centered method is to introduce students to course contents outside of the class so that students can engage at a deeper level in the classroom [1]. In other words, flipped learning

\footnotetext{
Authors E-Mail: (kifayat28@yahoo.com, tasweer2001@yahoo.com, ustchefei@hotmail.com, alveena280@yahoo.com)

* Department of Engineering Management, College of Electrical \& Mechanical Engineering, National University of Sciences \& ** Technology, Islamabad, Pakistan.
}

This is an open access article published by Mehran University Research Journal of Engineering and Technology, Jamshoro under the CC by 4.0 International License. 
method is supported by blended learning approach, and teaching strategy which reverses the conventional instruction by providing learning/instructional contents online available to students outside from the learning classroom. It brings all the activities into the classroom which is considered to be a homework in a traditional learning environment. Flipped classroom methodology is a new approach in which students watch and study online lectures and learning contents provided by the teacher. Students understand the contents and carryout study at their own time. In the classroom students engage in concept/practical implementation with the supervision of a teacher. The inverted classroom is based on studentcentered methodology and approach which is considered as a different method and perception including peerassisted learning, active learning concept and constructivism [2].

Active learning is a method in which students engage in the instructional process by means of different activities like exploring, communicating, analyzing, creating, reflecting and actually using new information or experience. In active learning, students are involved in conceptual learning activities which lead to a practical involvement of students in the processes. Through which different levels of student centered activities need to be completed by student involvement. Peer instruction is an evidence based interactive teaching [3]. Student centered approach and peer instruction is considered as a foundation of the inverted classroom. Peer instruction and active learning shifted the responsibility of learning from educator to student. Relatively flipped method is a new approach in education that focused on learner-centered instruction. The model helped and allowed administration and teachers to shape a dynamic process and move active-learning environment in the institution [4]. Student's attitude and engagement in learning is one of the basic factors for success of flipped classroom and to maintain quality learning in the class, teacher must give more contribution openings for students. Student support is required to be sufficiently structured. If not, there is a possibility that from the flipped classroom desirable results may not achieved, and it may take students to low learning situation because of low motivation and frustration in the classroom. Efficiency of the flipped approach can be improved by maintaining student's attitude and motivation [5]. It is important in the flipped classroom that the instructor should rely on multiple models and multiple approaches for the success of better understanding and learning such as small and short lectures for evaluation, group discussions and student's enquiry [6]. The flipped classroom activity must be designed so that it should provide maximum openings for learning and construct expressive individual knowledge. At the same time, it should provide an opportunity for quality cognitive skills like analyzing, evaluating and practical implementation [7]. Student-centered approach improves student thinking approach and ability. In the process students will be able to question from the course contents in their own words and they will be capable to understand and match it to their previous knowledge. When students start generating their own questions, it's proved that approach is effective and it stimulates students into quality thinking and engages practical understanding in student-centered method. Students generated questions engage students in learning activities and learning contents. They get more understanding and increase their interaction in the classroom. This positive result from active learning on students success has been examined in many areas including mathematics, language, sciences and reading [8]. The systematic and consistent use of collaborative technology makes the active learning model exceptional. Interactive technology like IRS (Instant Response System) acts as an educational facilitator. It provides platform for collecting student's responses. Interactive technology also supports stronger communication, socialization and sharing. 
Flipped classroom provides mutual collaboration and stronger communication [9]. Student's responses can be tallied and graphically displayed through IRS in the classroom simultaneously [10]. Students in the flipped classroom can direct their opinions instantly which identifies the students entrust in learning and at the same time teachers can see a larger picture of overall class improvement in actual time. [11]. Many researchers have observed the impact of IRS on learning and they have noticed a constructive erudition outcome. In cooperating education strategies and learning activities through flipped classrooms is a pedagogy and reinforced by technologies which will definitely encourage students learning, understanding, motivation, learning spirit, attitudes, learning commitment, engagement and will enhance their high order thinking ability in higher education teaching.

\section{LITERATURE REVIEW AND THEORETICAL FRAMEWORK}

\section{Learning Theories in Education Environments: Learning} theories are conceptual systems that portray the way in which the data is retained, prepared and held amid learning. The learning theories most commonly referred to in this context are briefly explained as follows:

Behaviorism: Behaviorism is based on perceptible changes in behavioral designs. It centers on an unused behavioral design being rehashed until it gets to be programmed. The learner depends on a teacher for the information [12].

Cognitivist: Cognitivist approach is based on the change in behavior through the consecutive advancement of an individual's cognitive abilities. In this approach a pretest is utilized to characterize a suitable learning way for each learner's profile.
Constructivism: Constructivism clarifies the way in which information is built. It centers on the development of information when the data is absorbed with the information procured by the learner [13].

Cooperative Learning: In cooperative learning, students work together in groups. The objectives are for students to understand how to contribute to a team, demonstrate personal responsibility, and additionally share responsibility for the results of the others. As students engage in conversation with others, they listen to varying considerations and suppositions.

Constructive Controversy: Constructive controversy is the effective key to decision making [13]. In making choices, alternate courses of action are proposed and considered; at that point, an agreement is agreed upon by students so as to which alternative would be most successful in understanding the issue [14].

Coop-Coop Approach: Another formal learning methodology is Coop-Coop. This procedure was made for the college classrooms. The students take either their own time, or lesson time to investigate, examine, and learn the basic concept. They make an introduction to their classmates to educate the subject. The teacher comes up with additional information or clarification at the conclusion of the introduction. All students within the course are held responsible for key data given within the introductions [15].

Peer Instruction: Mazur [3] started to compose around the advantages of Peer Instruction, in which students offer assistance to one another to study. Mazur [3] established that computer-aided teaching provided him more opportunities in course to perform as a teacher and guide, and he recognized that his understudies had higher accomplishment and were more fulfilled with their courses. In Mazur's strategy, conceptual multiple-choice 
questions are posted at some points of the lecture. Within the occasion that the concept shared by the students' responses is wrong, they are asked to turn to their neighbour to induce them of their answer. Mazur claims his strategy works best within the occasion that understudies get prepared a few times as of late lesson and after that test their application of data in a lesson where they have openings for well-off feedback. Peer instruction is considered to be a shape of the flipped classroom and gives an organized way to coordinate understudy arranging, in-class energetic learning, and affluent input openings[16].

Bloom's Taxonomy: Bloom's taxonomy categorization makes a pecking order to classify diverse learning. In numerous classrooms, instructors give space for recollecting and understanding and send the students to apply and analyse on their own. Traditionally a teacher's wisdom was essential to guarantee the student's success. Flipped learning in a general sense changes the teacher's part within the classroom. Working on the more troublesome abilities to apply and analysing within the classroom, the instructor is there to direct and give help at the point when student requires assistance. So instructors are imaginatively utilizing oneto-one coaching and innovation. This focuses the students to construct on what they know, assess diverse ways to apply their information, and make modern and unique works that exhibit what they have learned [17]. Fig. 1 shows the process of traditional classroom (a) vis-a-vis flipped classroom (b) as aligned with revised Bloom's taxonomy.

Blended Learning: Blended learning technique has also great impact on students learning and teaching process. Blended learning model is a learning process which is based on a combination of traditional classroom and activities in an online education environment. In a blended learning course, the students might go to a lesson instructed by a speaker in a conventional classroom setting, whereas too exclusively carrying out online components of the course exterior of the classroom[18].

TPACK Framework: It is an innovative integration system that identifies three sorts of information that has to be combined for fruitful education technology integration[19]. Fig. 2 explain technological pedagogical content knowledge framework to understand the relationships between technology, pedagogy, and content.

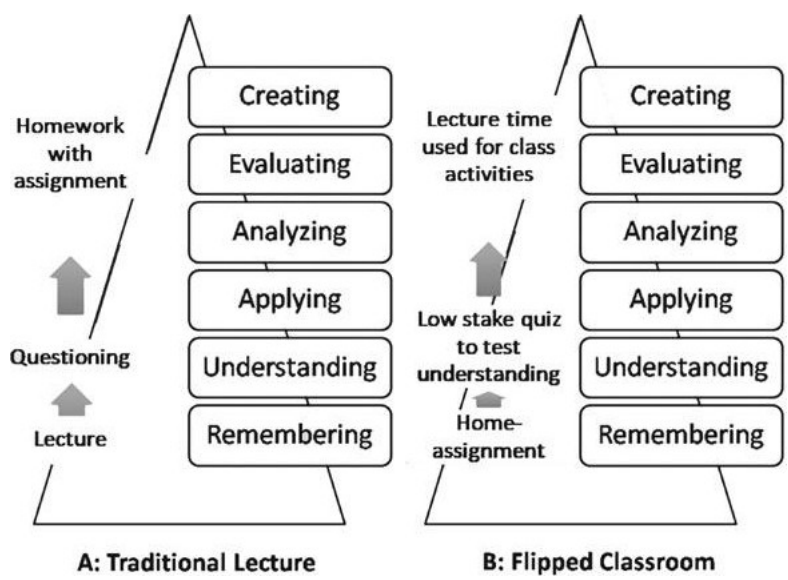

FIG. 1. CONNECTION BETWEEN TRADITIONAL AND FLIPPED CLASSROOM TO BLOOM'S TAXONOMY [17]

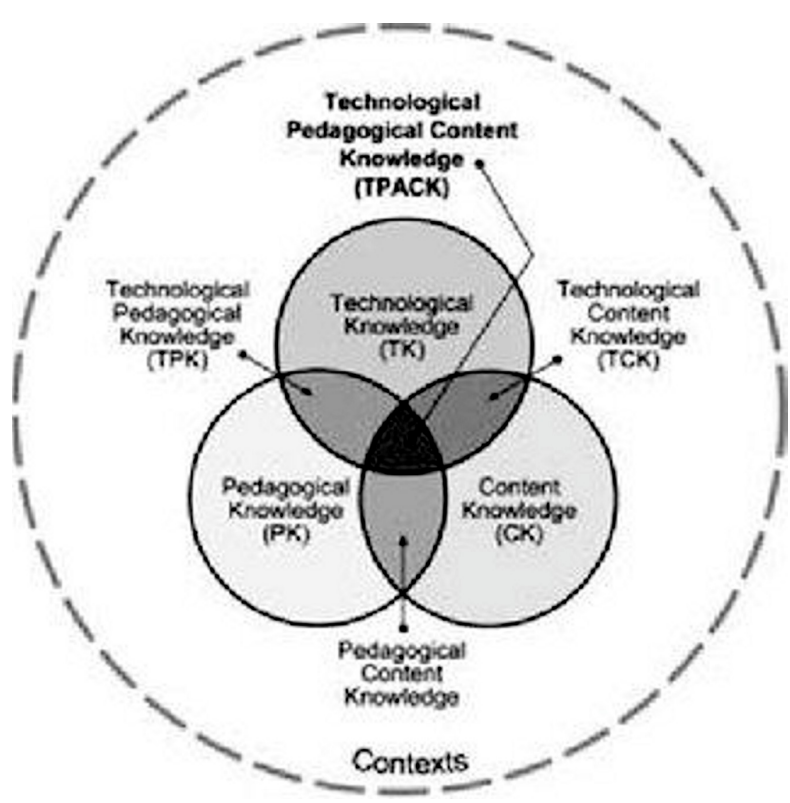

FIG. 2. TPACK FRAMEWORK [19]

Mehran University Research Journal of Engineering \& Technology, Volume 38, No. 3, July, 2019 [p-ISSN: 0254-7821, e-ISSN: 2413-7219] 
TEL (Technology-Enhanced Learning): The terminology TEL has emerged as a compulsion, to deal with the challenges popped up by the development of ICT (Information and Communication Technology) and its strength for greater access to education. The ultimate impact of ICT on education is still being discovered. It is the overall understanding and a common perception that technologies can "Enhance Learning" therefore the terminology TEL is progressively being used worldwide. With regards to the practice of ICT, the old term with a confusing variety of meaning "e-learning" has been subsumed in TEL. Clear statement about the actual meaning of TEL is rare to find, most commonly TEL is normally measured with infrastructure and equipment, like all available online services and systems that support teaching and learning [20]. The revised strategy has been defined for TEL as "Enhancing instruction and knowledge using of technology". TEL will bring three levels of potential benefits.

Enhancement: Improvement in the existing practices/ processes and the results.

Efficiency: Improvement in the ongoing processes in terms of cost effective, time effective for positive outcome and result.

Transformation: To work out and identify positive changes in existing procedures and suggesting new affective processes.

Understanding TEL: TEL or technology inspired learning or technology enabled learning commonly used terms still do not have a specific commonly accepted definition. TEL is defined as the solicitation of ICT into instruction and knowledge, which keep up instruction and knowledge processes, delivery mechanism and design parameters to enhance knowledge. TEL has the capability and capacity to transform education and bring improvement in global education in many folds. TEL encompasses all the broadly synonymous terms like e-learning, online, distance education, internet based learning, multimedia education, web based learning, etc. to be more precise TEL is referred to the use of ICT and electronic media in learning. Online education developed from a Gutenberg era, mail system printing system which supports high interactive and low cast learning in the shape of time and space with equal opportunities [21]. Online education is dynamic in nature and does not follow the single paradigm mode. One of the most popular form of TEL is e-learning, e-learning services commonly used in schools, colleges and universities, e-learning is used by many institutions to solve authentic teaching and learning problems [22].

Distant learning or off the class learning is the most common form of TEL facility in universities, education and training institutions, as well as in industries. Moreover, from the last few decades, distant and elearning dominated the on-line education and a new form of TEL emerged, new innovative solutions were introduced to widen more participation, like open resources. In education institutions TEL concept is changing the landscape of learning services, by introducing innovations in traditional practices. TEL concept is getting emphasis in education institutions [23].

Strayer Model: This framework is used for exploring learning movement in a classroom that's organized utilizing the flipped classroom approach. Dynamic learning environment amid course time is the essential inclusion of flipped classrooms [24].

It identifies that learner not yet progressive into an area of speciality may lead to student discouragement and lack of attention in the contents, making prospects of speculation impractical. Therefore, it may be right that less established learner can be disappointed by anxieties for their period and devotion, the disagreement that 
learner in overall cannot adjust to this approach until they are progressive is not reinforced by the indication. Freshmen are frequently taking a diversity of programs in different discipline classes, which mandate a diversity of teaching approach. In addition, there are also classes based on pre-learning and in class discussion dependent like literature. "This aspect has become the foremost corner stone for the use of technology and strategy in order to utilize this model in higher education sector". Fig. 3 represent learning through activity using education technology and flipped methodology for conceptual study.

Flipped Inspired Technology Environment: To achieve a best effective learning environment, five variables that have great impact on achieving effective learning environment are, Educational Technology, TEL Strategy, Student Question Generation, Content Analysis and Competitive Benchmarking, Instant Response System.

Educational Technology: Technology can be an effective apparatus for changing learning. Technology acts as a catalyst for changes, change in work situations, developing new effective strategies, learning approaches, inquire about the field and in utilizing information. It provides support and develops contacts amongst

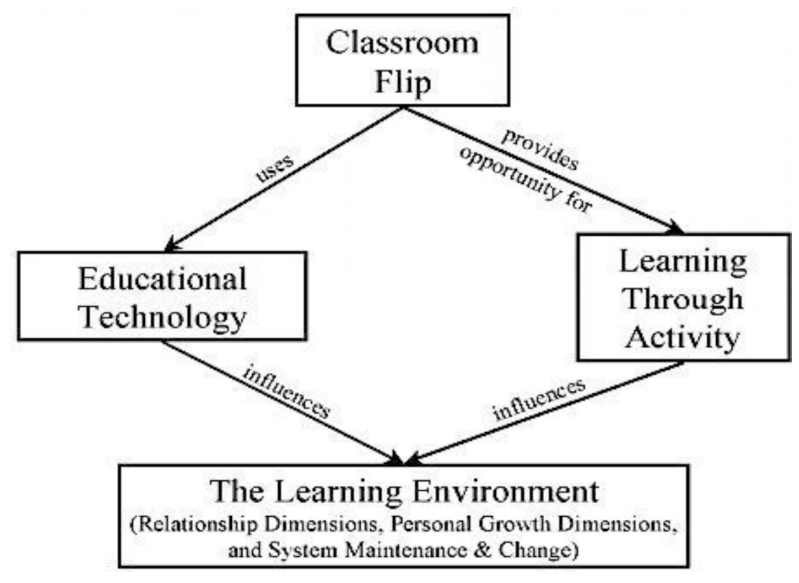

FIG. 3. STRAYER MODEL [24] teachers and students, re-evaluate our methods to education and change learning encounters to fulfil the requirements of all students for changing learning. To understand and fully appreciate the advantages of technology in our learning structure and to give reliable education familiarities, teachers require to practice technology effectually in their preparation. Besides, learning partners should commit to work in collaboration to utilize technology to progress learning. According to US Department of Education [25], these associates include innovators, teachers, supervisors, and other educators, specialists, officials, fund providers and improvement inventors. In today's era of communication and IT with current available contact to a large amount of contents of information, the creative practices of technology delivers a numbers of experiments and new openings for the student. The real practice of education technology to improve precarious intellectual assistances will make the learners of 21 st century.

Today's children utilize specialized electronic gadgets from their primary stage so that any new and unused learning technologies at primary level will not be an issue.

In the field of instruction social media provide and democratize education by giving larger space to information and concepts which give noteworthy openings to create more capable societies and to spread knowledge. They moreover yield education outside the class into the active space of students [24]. A great advantage is the effect of digital technologies that promotes the interaction between teacher and learner. Learners are enabled through their more noteworthy recognition and competence with the modern computerized technologies. With a lot of benefits modern technologies carry some risks as well [25]. Also a question raises whether internet is making us doltish, or damaging our protection and making a digital panoptic on [26]. 
To influence learning experience in children's education, technology focuses on five areas that are the educator's regard of the program and capacity to bolt in children's learning. Ease how to utilize, Intelligence amongst the youngster, programs and the credibility that a software database observers the development of the youngster.

\section{Technology Enhanced Learning Strategy: TEL strategies} are used to identify a vast field of modern technologies which are used to help and mediate educational events, to introduce technology in education field and enhance learning. TEL pointed to the utilization of innovation to help and upgrade education preparation. TEL situations empower permission to a number of tools, educational devices and interaction offices, so that they can be perfect positive education atmospheres that empower the understudies to end up more effectively and intricate in emerging deep learning and compassions. Technology provides large number of openings and opportunities for advanced study, and equally improving current system and providing novel potential. The last two decades have seen critical improvement in the use of technology for higher education at undergraduate and postgraduate levels all over the world [27].

TEL strategies are introduced in educational institutes by which learners can be provided with enhanced or transformed educational experiences. The higher education funding council England in their computer based strategy concluded three degrees of potential benefits of technology enhanced learning, (1) Capability, whereby existing processes can be improved in a max cost effective, duration efficient, temperate, or versatile style; (2) Enhancement, which upgrades current procedures and outputs and (3) Transformation, representing abrupt modification in the present procedures or the introduction of cutting edge processes. Modern technologies can be planned to create and encourage higher order learning aptitudes, like problemsolving, decision-making and critical thinking.

SQG (Student Question Generation): SQG has great impact on effective learning environment. It basically clarifies that how much effective knowledge is transferred to students and how clear they are on concepts that are delivered. It improves student learning capabilities because students try to generate questions by thinking in depth, or by reading from textbook on the concept. Inquiring students to create questions alongside the responses grounded on the education content may offer assistance understudies create abilities by deliberately coordinating their consideration to the target information. Asking queries mandate learners to recollect data from the studied; the dispensation level questions need learners to draw associations between the information, and by asking the queries learners go outside the information to imagine, generate, and appraise. Learner initiated queries improve advance-order education by demanding them to examine data, analyse different concepts, and express their thoughts about the concept. Learner queries show that learners have perception regarding the offered thoughts like a particular knowledge they know. The queries can disclose many things about the feature and standard of learners' intellect and consideration. SQG is a basic perceptive methodology, as the act of constituting queries it shows the consideration of learners on learning material and fundamental thoughts, examining whether the learning material is satisfactory and useful. Three sorts are classified agreeing to the cognitive level of understudy questions, input, preparing, and yield. The input level queries request learners to review data from sensitive information, the processing level queries need understudies to attract connections between the information, and yield level queries need understudies to go past the information to hypothesize, make and assess [28]. 
Questions can improve the importance of learners' education and knowledge, and what students would like to know. Student Question Generation methodology has positive impacts with respect to understudy execution like understanding. Educational inspiration, encouraging states of mind to topic substance, more different and adaptable considering, problem-solving capacities, and intellectual and metacognitive procedure advancement [29].

\section{Content Analysis and Competitive Benchmarking:}

Benchmarking is one of the strategies higher education can utilize to assist them to accomplish the objective of productivity and cost-effectiveness in optimizing the assets accessible to support learning. Benchmarking is strongly related to quality perspectives and the advancement of quality administration in organizations. It goes beyond the conventional competitive analysis to not only reveal what the best practices are but moreover to get a clear understanding of how best practices are utilized and implemented. Beside its application in other fields, the field of education can also be improved by applying benchmarking since most of the processes, functions, and practices are by and large utilized in every educational institute. Benchmarking in education happens when quantifiable measures are set for learning. The technique of benchmarking is very important for theoretical aspect as well as practical approach. Which is being utilized for moving forward for managerial forms and also as guidelines for universities by analysing forms and approach in learning places and adjusting the strategies and methods [30]. Benchmarking methods can be categorized into 4 stages: First step is preparation of the study which includes, recognizing and method of measure, and choosing other organization to measure this process. In 2nd step which is conducting the research, benchmarking process information is collected using essential study regarding the university, or other establishments under examination. In 3rd stage which is examining the information, comprises analysing the information accumulated to estimate the study results and to create proposals. The contrasts in execution among the organizations which are benchmarked offer assistance to recognize the method that prepares the pioneers in their commitment. In fourth step that is adjusting the results to the domestic organization that's leading the research, these enablers are adapted for improvement of system.

Policy Benchmarking: The assessment of approaches amongst diverse frameworks has the latent to lead to an improved understanding of the connections amongst strategy and outcomes, producing education and the progress of up-to-date approaches for enhanced execution.

Metric Benchmarking: This type of benchmark is utilized to show execution of data in a way that nations can distinguish the qualities and shortcomings inside their own advanced learning systems and relate it to execution beside other nations. This method differentiates with traditional metric benchmarking in which an association sets up how well it performs comparative to a benchmark 'target'.

Practice Benchmarking: Data on advanced learning usage will be displayed to empower the evaluation of advanced learning framework execution and an improved knowledge of the motives behindhand the execution. This type of methodology will recognize which practices yield superior results and benefit nations share modern thoughts and implementation.

IRS (Instant Response System): IRS which is also called the classroom response system. This system is utilized to assemble learner's answers inside the class on the lecture [31]. IRSs are utilized to occupy learners' support 
and attentiveness in the lesson, moreover can improve their education encounters, and learning. Different researches have illustrated the different impacts of IRSs on students education encounters in TEL classrooms over numerous courses in advance instruction, such as expanding learners' consideration, [32], interactions, and improved education efficiency [33]. In any case, it was jagged that utilizing an IRS needs additional learners' cognitive vitality and cooperation. IRSs escalated the magnitude and capacity of flipped classroom model idea that was student-centered learning. IRSs not only effects learners' dialogue forms and intangible education results, but moreover have constructive impacts on learners' passionate, motivational attitude and cognitive encounters within the class. IRSs also have an encouraging effect on learners' inspiration, students' attitudes and student's engagement in education. During learner debates earlier or afterwards responding the questions, IRS will efficiently be backing peer instruction and considerations which effectively increase the student's participation in class and interaction between teacher and student. Student response time really has great importance in effective learning education environment, it is a common thinking that if a student is responding or taking part in class activities or asking questions during lecture actively then it means that everything is going well and lecture seems to be interesting for students. A lecture is the foremost commonly utilized educating method and may be the foremost viable strategy to communicate with number of students. The normal student regularly pays attention for the primary 10-20 minutes of a lecture.

The utilization of innovation such as understudy reaction frameworks permits for more student engagement and interaction, which may progress the quality of students' learning. An Effective learning environment can also be achieved when student question generation and student response time both are active. [34].
In addition, students who are not sure or who may be less slanted to talk in open are more likely to take an interest in utilizing the understudy reaction framework since all reactions are mysterious. Improving interaction within the classroom can lead to way better and more viable learning. Verbal addressing and answering, which is the foremost common shape of interaction between teachers and students, is used to look in and include students effectively within the classroom, assess students' learning and give instructive criticism to understudies.

Effective Learning Environment Motivation: Is one of the basic and important aspect in education system and approach. For any learning, motivation plays an important role. Students must be highly motivated for any type of learning. Motivation will remain the driving force which will mark learners attached with it in all situations so they may be having problem in accepting the data being offered in exercise. Certainly, any difficulty with education can be controlled if the learner's motivation is tall sufficient. It is imperative, the teacher also needs to be extremely motivated to impart. They should have an extreme wish to narrate data throughout the implementation in a way learners can appreciate. When learners are having difficulties, the teacher must be inspired enough to devote the additional period it takes to guarantee that the learner finally knows existing contents. This may be extremely puzzling since learners' ability levels differ [35]. Our course contents motivate both ways. The interesting and explanatory slide display, the lecture nature of the guide, the related rehearsal trainings, and the extremely organized key ideas method will capture and grip your learners' consideration, and make it easy and informal for the student to remain motivated. 
Presentation is an important aspect and just like heart of training activities. It depends on the teacher's preparation, if the teacher prepares his presentation well and presents it in a perfect way to student, this will be easy for the student to understand. Main presentation must have good explanation and quality like teacher's discourses, demonstrations, replications, perception, thinking on quality slides [36].

\section{RESEARCH METHODOLOGY DESIGN}

Research design consists of "a number of coherent conclusion creating selections" likewise, explained research design as, "research design is a main strategy that postulates the procedures and actions for gathering and examining the required data. Research design offers a structure or strategy of action for the study". At the same time established a reasonable study onion to describe study plan as shown in Fig. 4. Research onion consists of three major fragments: Philosophies, Approaches and Research design [37].

Philosophy: Philosophies of the research are characterized in 4 kinds as: Realism, Positivism, Interpretivism and Pragmatism.

Realism type of philosophy liked to scientific examination, it completely relates to the student sensation supremacy, what student understand and the sensation properties perceived by the researcher mind are supposed to be correct.

Deceptions may extremely moderate this type of philosophy. In Positivism philosophy research is normally followed, just like usual researches and take to expansion of rules, just like general and social sciences. Interpretivism philosophy support the comparative situation of the student to the study and inferences are drawn upon explanation of diverse social players (nonobjective) replies in certain situation. Pragmatism philosophy promote the circumstances where student's study scope is comprehensive spread and, also should have probably, where study query clearly does not outline study philosophy that it is may be Positivist, Realism or Interpretivism to discover the technical and impartial answer to the study question. Fig. 4 the research onion was developed by Saunders [38]. It illustrates the stages that must be covered when developing a research strategy.

Research Approach: There are two main branches of research approach, i.e. Deductive approach also called top down approach, the other branch is Inductive approach, which is also called bottom up research approach [39]. Hypothetical variation amongst these two methods are concisely defined as under and appropriate method for this research is defined. The main two types of research approach is almost opposite in approach and direction of analysis therefore, inductive approach is also called hill climbing or bottom up, whereas deductive approach also called water fall or top down, at the same time both research approaches are different with regards to time frame for completion. Deductive approach is used for this paper.

Deductive Research Approach: Deductive approach act normally from the analysis of more general to the very specific. Occasionally this is casually named a "top down" method. Assumption follows reasonably from evidences, existing evidences. This type of method is created on earlier information where relevant theory overtures and study limits are stretched over experiential testing of planned theory established based on literature examination. For my paper I have selected deductive approach as per the above justifications. A theoretical framework is established over literature review and hypotheses are planned on the basis of literature review. 
Time Frame: Mainly we have two kinds of time horizons, to assume a research study, in management study. One is recognized Snap shot and also called Cross Sectional, the other type is diary and longitudinal. Cross sectional, the scholars use some opinions and judgments at the same time to abstract effects, on the basis of these readings, where, in longitudinal study keep on noting observations for some time period, definite / indeterminate in study period, and then abstract outcomes by means of the already taken observations. My research paper based on cross sectional survey method due to available time and financial limitations.

Survey Questionnaire: The research questionnaire is planned and designed to check the connection anticipated in the study framework. The research questionnaire scale includes multi objects. To check the dependability, accuracy and validity of selected measurement scale, essential procedures are engaged in the correct direction as well as have the best existing literature research guidelines. The research questionnaire preparation method consists of three main steps. At 1st step, all pertinent literature is studied and explored in detail to discover the previously established measures with good extent of consistency, accuracy and validity [40]. Research questionnaire objects are moderately adjust with regards to educating technology, technology enhanced learning strategy and effective learning environment. At 2 nd step, experts from the education field (VC Universities) were asked to provide feedback, regarding survey instrument suitability with respect to effective learning environment. Their feedback, with regards to significance of few objects and items, removal of any biases and research questionnaire structure etc., is merged in the research questionnaire. Research questionnaire object and items' linguistic 'English' were not altered, as the entire respondents are using 'English language' as worldwide communication linguistic. At 3rd step, three high-ranking academic peer $(\mathrm{PhD})$, and four $\mathrm{PhD}$ researchers are requested to analyses the research questionnaire objects and items to eliminate any academic mismatch. Table 1 present a complete summary of research design parameters including research type, approach target population, sampling technique and analysis methods.

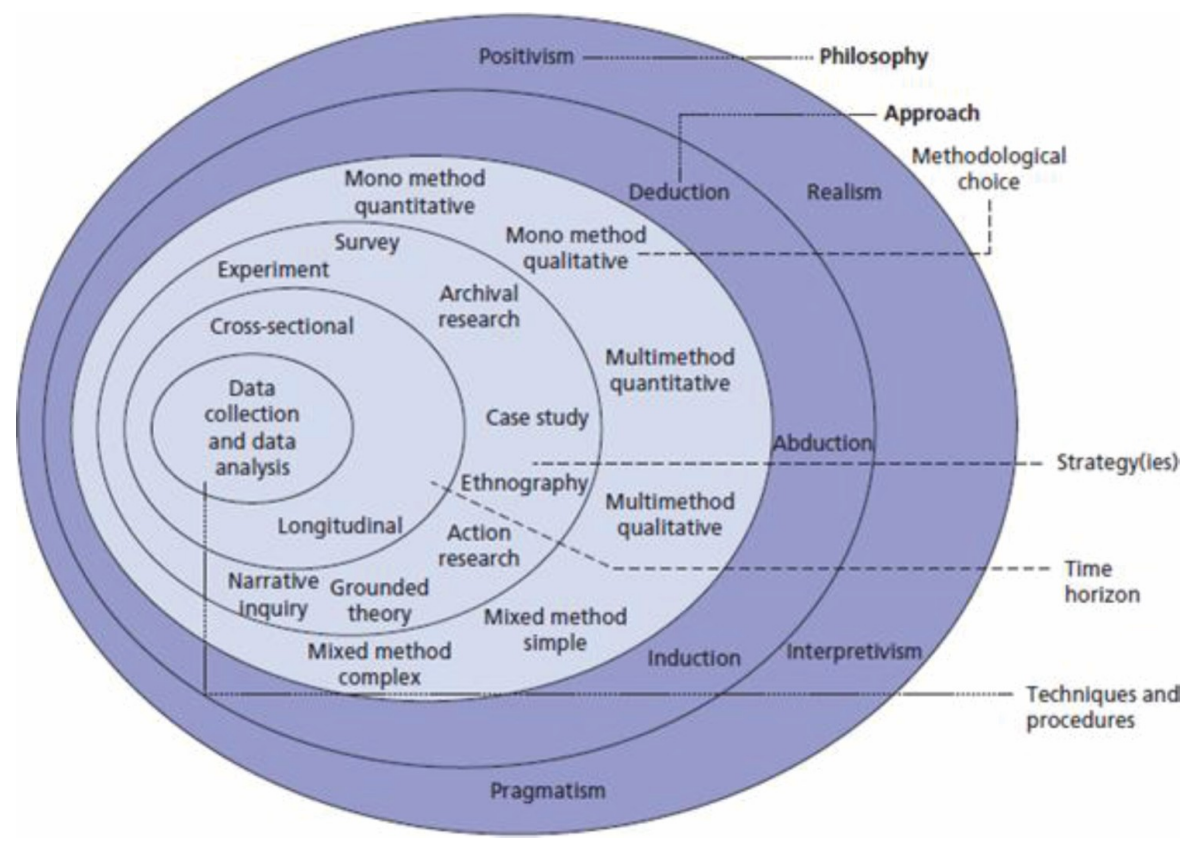

FIG. 4. RESEARCH ONION DIAGRAM BY SAUNDERS [38] 


\section{RESEARCH GAPS}

(i) The core aspect of technology integration to enhance flipped classroom effectiveness has not been critically examined as per the literature.

(ii) The application of TEL strategies to enhance ELE is an area where applied research presents a void

(iii) Active learning implementation and system acceptability explored in few studies

(iv) The lack of acceptance for un-conventional teaching methodologies combined with lack of adequate technology driven mechanisms to fulfil the educational needs is an area to be focused upon, is addressed in this research.

(v) A comprehensive TEL framework, based on identified factors for ELE need formulation.

\section{RESEARCH QUESTIONS}

(i) What is the impact of TEL on ELE?

(ii) What are the main factors which influence ELE?

(iii) Can a new approach of active learning strategy e.g. FL can improve ELE?

(iv) What is the impact of "acceptance towards unconventional learning" on ELE as a moderator?

\section{RESEARCH OBJECTIVES}

(i) To estimate the impact of TEL on overall learning environment.

(ii) To determine the key factors that influence ELE.

(iii) To observe this phenomenon under the umbrella of strategy implementation, formulation and pointing out the key pillars of that strategy.

(iv) To have a firsthand knowledge about the use of FLIPPED learning methods at institutes of higher learning i.e. universities and technical colleges.

\section{PROPOSED FRAME WORK AND DATAANALYSIS}

Fig. 5 represent proposed technology enhanced framework for effective learning environment powered by flipped methodology.

Variables' Descriptive Statistics: Variable descriptions are given in Table 2. All the factors are selected through frequency method, independent and dependent variables are identified and extracted from literature review.

Data Normality (Exogenous Variables): Table 3 Skewness, Kurtosis and Shapiro wilk test result are given for independent variable which shows that data is parametric.

TABLE 1. RESEARCH DESIGN SUMMARY

\begin{tabular}{|c|c|}
\hline Research Type & Mixed Methods: Qualitative exploration leading to Quantitative \\
\hline Research Approach & Deductive Approach \\
\hline Research Strategy & Cross-sectional Survey \\
\hline Survey Population & Undergraduate Students in HEIs \\
\hline Sampling Technique & Sampling Technique: Proportionate Stratified Sampling, \\
\hline Data Collection & Self-administered questionnaire \\
\hline Responses & Regression analysis, Structural Equation Modelling, Moderation, F-max (Hartley's) \\
\hline Analysis Methods & (1), random generator 450 Responses \\
\hline
\end{tabular}

Mehran University Research Journal of Engineering \& Technology, Volume 38, No. 3, July, 2019 [p-ISSN: 0254-7821, e-ISSN: 2413-7219] 
Fig. 6 shows histograms of the independent variables.

All the histograms of the variable are normally distributed.

Data Normality: (Endogenous Variables): Table 4 Skewness, Kurtosis and Shapiro wilk test result are given for independent variable which shows that data is parametric.
Fig. 7 shows histograms and Q-Q plot of the dependent variables. The histogram and Q-Q plot of the variable is normally distributed.

No serious issues observed with data normality as Skewness, Kurtosis and Shapiro-Wilk are within limits \pm 2 to \pm 3 and $p$-value $>0.05$ respectively.

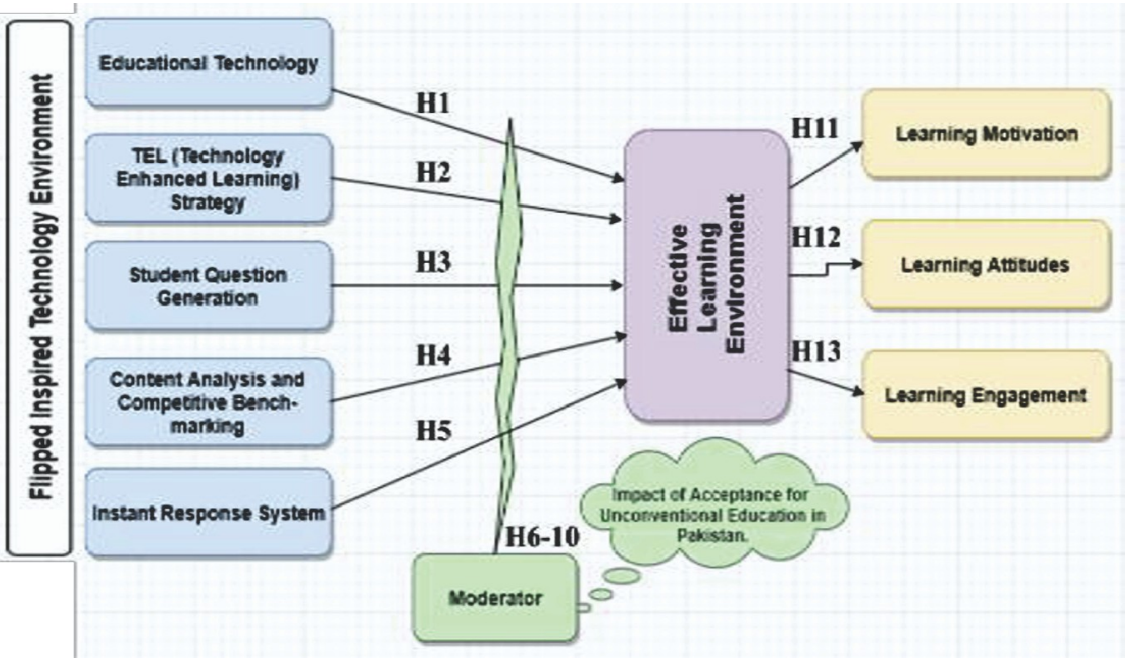

FIG. 5. PROPOSED TECHNOLOGY ENHANCED LEARNING FRAMEWORK

TABLE 2. ENDOGENOUS AND EXOGENOUS VARIABLES

\begin{tabular}{|c|c|c|}
\hline No. & Construct & Definition \\
\hline 1. & Education Technology & Facilitating learning, using appropriate technological processes and resources \\
\hline 2. & Technology Enhanced Learning Strategy & Using technology to facilitate and support innovative teaching and learning practices \\
\hline 3. & Student Question Generation & Promoting students' comprehension, improve critical and creative thinking skills \\
\hline 4. & Content Analysis and Competitive Bench Marking & Compare their existing performance against others \\
\hline 5. & Instant Response System & Technology that promotes and implements active and cooperative learning \\
\hline 6. & Effective Learning Environment & Enables students to meet their learning needs and interests
\end{tabular}

TABLE 3. NORMALITY TEST VALUES FOR INDEPENDENT VARIABLES

\begin{tabular}{|c|c|c|c|}
\hline Variables & M (SD) & Skew & Kurtosis \\
\hline Education Technology & $5.45(0.50)$ & 0.050 & -0.298 \\
\hline Technology Enhanced Learning & $5.44(0.49)$ & -0.035 & -0.053 \\
\hline Student Question Generation & $5.48(0.29)$ & 0.124 & -0.127 \\
\hline Content Analysis and Benchmarking & $1.97(0.30)$ & -0.025 & 0.088 \\
\hline Instant Response System & $5.42(0.51)$ & 0.050 & 0.151 \\
\hline
\end{tabular}

Mehran University Research Journal of Engineering \& Technology, Volume 38, No. 3, July, 2019 [p-ISSN: 0254-7821, e-ISSN: 2413-7219] 

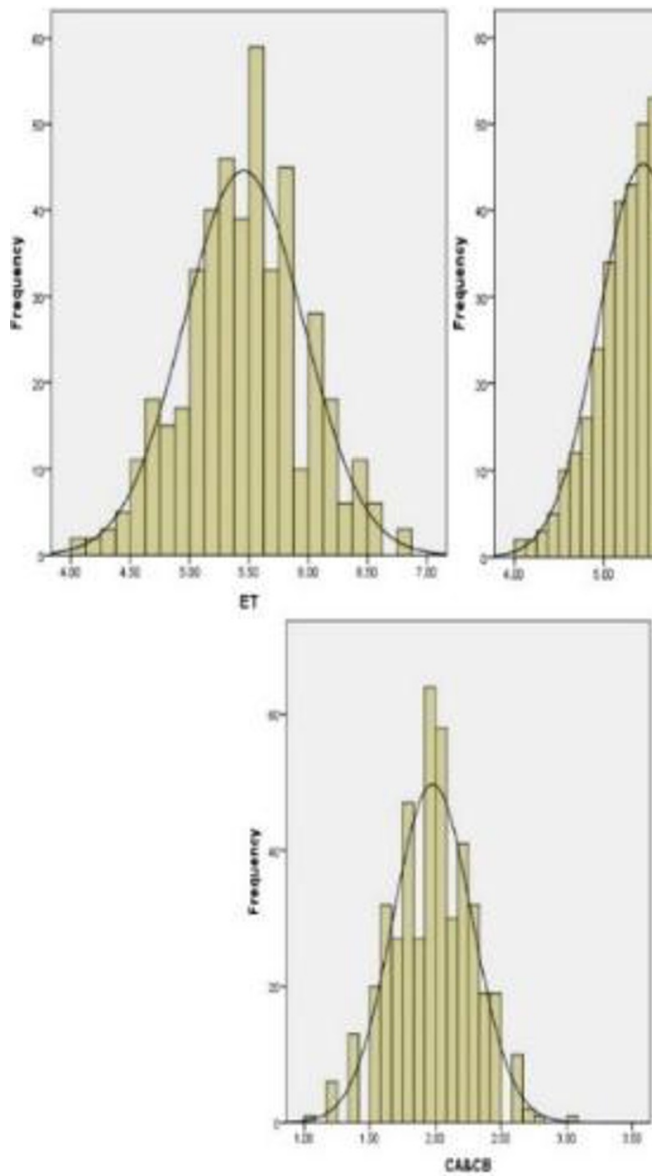

FIG. 6. HISTOGRAM OF VARIABLES

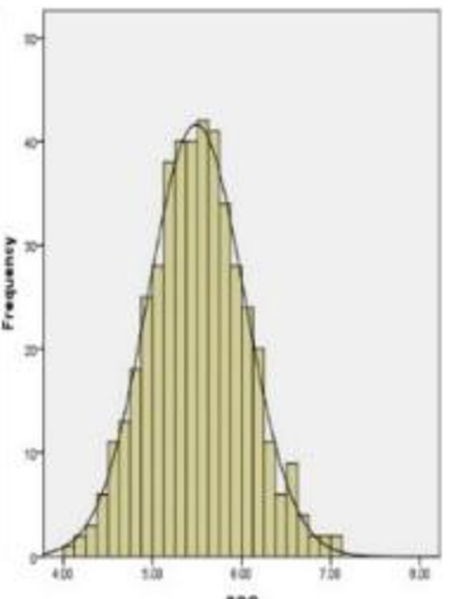

500

TABLE 4. NORMALITY TEST VALUES FOR DEPENDENT VARIABLE

\begin{tabular}{|c|c|c|c|c|}
\hline Variables & M (SD) & Skew & Kurtosis & Shapiro \\
\hline Effective Learning Environment & $5.45(.46)$ & -0.079 & -0.131 & 0.278 \\
\hline
\end{tabular}
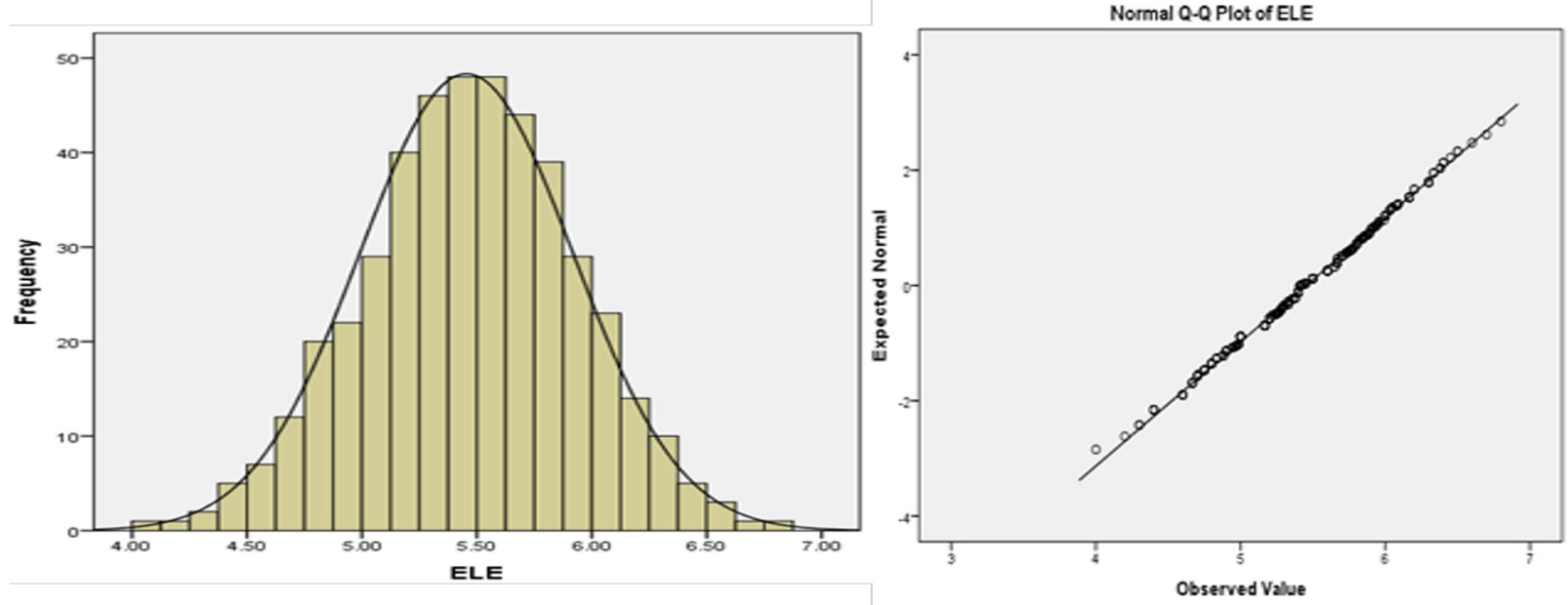

FIG. 7. HISTOGRAM OF DEPENDENT VARIABLE

Mehran University Research Journal of Engineering \& Technology, Volume 38, No. 3, July, 2019 [p-ISSN: 0254-7821, e-ISSN: 2413-7219] 
Validity and Reliability of Scale: Validity and reliability of scale is identified in Table 5. All the values are with the in the range which shows that Scale is reliable and consistence.

Regression Modelling Results: Tables 6-7, represent regression estimates and standardized and unstandardized coefficient of the variables. $\mathrm{R}$ square value is $56 \%$ and standard error of the estimate for the model is $53 \%$.

Path Diagram without Moderator: Fig. 8 display path diagram without moderator using structure equation modelling tool, the R-square values are mentioned at the top of variables while regression value is reported with single arrow head. Correlation is denoted with double arrow head.

Table 8 represent regression estimate and standard error between dependent variables and dependent variables.

Path Diagram with Moderator: Fig. 9 display path diagram with moderator using structure equation modelling tool, the R-square values are mentioned at the top of variables while regression value is reported with single arrow head. Correlation is denoted with double arrow head.

TABLE 5. VALIDITY AND RELIABILITY OF SCALE

\begin{tabular}{|c|c|c|c|c|}
\hline Construct & $\begin{array}{c}\text { Construct Reliability } \\
(\mathrm{CR})\end{array}$ & $\begin{array}{c}\text { Item Loadings } \\
\text { (Minimum-Maximum) }\end{array}$ & AVE & 0.637 \\
\hline Education Technology & 0.766 & $0.761-0.839$ & 0.764 \\
\hline Technology Enhanced Learning & 0.737 & $0.564-0.852$ & 0.727 \\
\hline Student Question Generation & 0.757 & $0.696-0.734$ & 0.509 \\
\hline Content Analysis and Benchmarking & 0.811 & $0.700-0.792$ & 0.750 \\
\hline Instant Response System & 0.731 & $0.637-0.773$ & 0.806 \\
\hline
\end{tabular}

TABLE 6. REGRESSION

\begin{tabular}{|c|c|c|c|c|}
\hline \multicolumn{3}{|c|}{ Model Summary } & Adjusted R Square & Standard Error of the Estimate \\
\hline Model & $\mathrm{R}$ & R Square & 0.352 & 0.53106 \\
\hline 1 & 0.517 & 0.567 & \\
\hline
\end{tabular}

(a) Predictors: (Constant), Education Technology, Technology Enhanced Learning, Student Question Generation, Content Analysis and Benchmarking, Instant Response System

(b) Dependent Variable: Effective Learning Environment

TABLE 7. COEFFICIENT

\begin{tabular}{|c|c|c|c|c|c|}
\hline \multirow{2}{*}{ Model-1 } & Unstandardized Coefficient & \multicolumn{3}{|c|}{ Standardized Coefficient } \\
\cline { 2 - 6 } & $\mathrm{B}$ & Standard Error & Beta & $\mathrm{T}$ & Significant \\
\hline Constant & 2.113 & 0.338 & & 6.25 & 0.000 \\
\hline Education Technology & 0.352 & 0.046 & 0.152 & 3.29 & 0.001 \\
\hline Technology Enhanced Learning & 0.255 & 0.047 & 0.268 & 5.41 & 0.002 \\
\hline Student Question Generation & 0.329 & 0.045 & 0.142 & 2.88 & 0.004 \\
\hline Content Analysis and Benchmarking & -0.106 & 0.083 & -0.052 & -1.28 & 0.199 \\
\hline Instant Response System & 0.214 & 0.045 & 0.120 & 2.48 & 0.004 \\
\hline \multicolumn{7}{|c|}{ Negative coefficient shows negative impact } & \\
\hline
\end{tabular}

Mehran University Research Journal of Engineering \& Technology, Volume 38, No. 3, July, 2019 [p-ISSN: 0254-7821, e-ISSN: 2413-7219] 
Table 9 specify covariance values with in independent variables which defined that exogenous variables are not related with each other.

Moderation Results: Table 10 regression estimates are compare with or without moderator, all the values are improve for moderating effect.

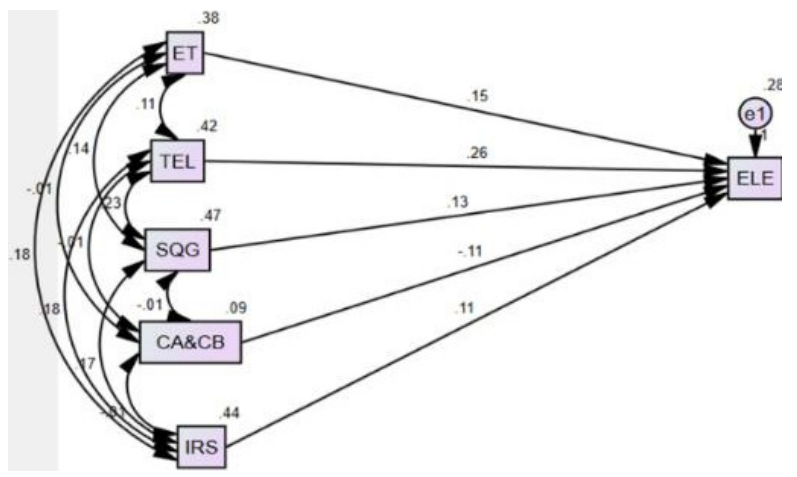

FIG. 8. PATH ANALYSIS WITH MODERATOR
Dependent Variable Analysis (Out Comes): In the framework, the dependent variable is further divided into three entities:

(i) Learning Motivation - X

(ii) Learning Engagement - Y1

(iii) Learning Attitudes - Y2

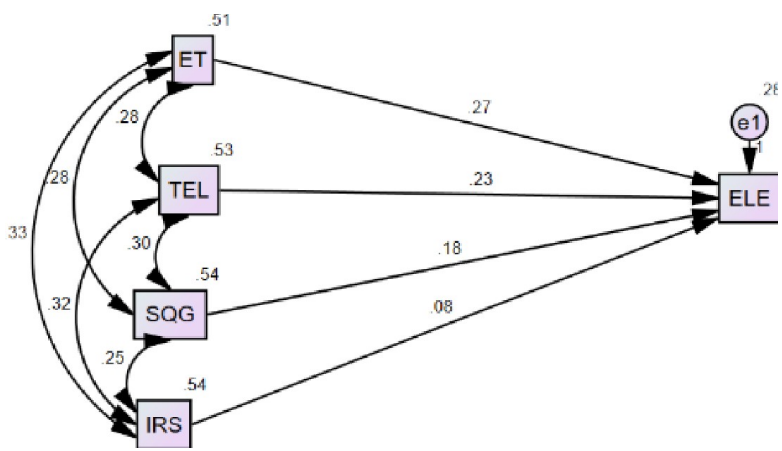

FIG. 9. PATH ANALYSIS WITH MODERATOR

TABLE 8. REGRESSION VALUES OF DEPENDING VARIABLES WITH INDEPENDENT VARIABLES

\begin{tabular}{|c|c|c|c|c|}
\hline \multicolumn{5}{|c|}{ Regression Weight } \\
\hline \multirow{3}{*}{ Dependent } & Independent & Estimate & SE & Standardized \\
\hline \multirow{4}{*}{ Effective Learning Environment } & Education Technology & 0.15 & 0.05 & 0.15 \\
\cline { 2 - 5 } & Technology Enhanced Learning & 0.26 & 0.05 & 0.27 \\
\cline { 2 - 5 } & Student Question Generation & 0.13 & 0.04 & 0.14 \\
\cline { 2 - 5 } & Content Analysis \& Benchmarking & -0.11 & 0.08 & -0.05 \\
\cline { 2 - 5 } & Instant Response System & 0.11 & 0.04 & 0.12 \\
\cline { 2 - 5 } & Effective Learning Environment & 1.00 & - & - \\
\hline
\end{tabular}

TABLE 9. COVARIANCE VALUES OF INDEPENDENT VARIABLES

\begin{tabular}{|c|c|c|c|c|}
\hline \multirow{2}{*}{ Covariance } & Standard Error & Correlation \\
\hline \multirow{3}{*}{ Education Technology } & Variable2 & Estimate & 0.04 & 0.54 \\
& Technology Enhanced Learning & 0.28 & 0.04 & 0.53 \\
\cline { 2 - 5 } & Student Question Generation & 0.28 & 0.04 & 0.62 \\
\cline { 2 - 5 } & Instant Response System & 0.33 & 0.04 & 0.57 \\
\hline \multirow{2}{*}{ Technology Enhanced Learning } & Student Question Generation & 0.30 & 0.04 & 0.59 \\
\cline { 2 - 5 } & Instant Response System & 0.32 & 0.04 & 0.46 \\
\hline Student Question Generation & Instant Response System & 0.25 & & \multicolumn{2}{|c|}{} \\
\hline
\end{tabular}

Mehran University Research Journal of Engineering \& Technology, Volume 38, No. 3, July, 2019 [p-ISSN: 0254-7821, e-ISSN: 2413-7219] 
These entities are further analysed for the effect of dependent variable (Effective Learning Environment) on $\mathrm{X}, \mathrm{Y} 1$ and Y2. The three entities of dependent variables are tested using the mixed model approach, $\mathrm{F}$ (MAX) or HARTLEY'S test is used as part of dependent variable analysis for three variables. The variance of dependent variable across the three subdivided entities is checked as per this test. The variance of the FIRST TWO VARIABLES are HOMOGENEOUS which indicates that the effect of Effective Learning environment on the first two outcomes is evenly distributed and hence dependent variable equally effects the two entities.

Hypothesis Testing Results: Table 11 explains hypothesis testing results, H13 is not supported. Rest all the hypothesis are supported.

\section{RESEARCH FINDINGS}

(i) This research reveals the incline towards enabled environment of active learning (ii) This research shows that the concept of FLIPPED methodology can become a base for knowledge enhancement and student engagement

(iii) This research shows that Technology enhanced learning strategies show a great potential in making effective learning environment possible

(iv) This research depicts that instant response mechanisms if installed in classrooms enable the learners to improve each other's potentials

(v) The activities done within the learning environments have to be instantly monitored in order to ascertain the effectiveness

(vi) The outcome of this research also makes prudent inquiries as regards to the influence of breaking social norms of traditional learning

(vii) The outcome of this research reveals that the traditional learning methodologies cannot cope up with the technological advancements and active learner has to be a product of technology driven un-conventional or flipped environments

TABLE 10. REGRESSION WITH / WITHOUT MODERATOR

\begin{tabular}{|c|c|c|c|c|c|}
\hline Independent Variables & $\beta$ & $\mathrm{t}$ & Independent Variables & $\beta$ & $\mathrm{t}$ \\
\hline Education Technology & 0.152 & 3.294 & Education Technology & 0.268 & 3.748 \\
\hline Technology Enhanced Learning & 0.255 & 5.419 & Technology Enhanced Learning & 0.226 & 3.208 \\
\hline Student Question Generation & 0.129 & 2.884 & Student Question Generation & 0.182 & 2.809 \\
\hline Content Analysis \& Benchmarking & -0.106 & -1.287 & Instant Response System & 0.078 & 1.109 \\
\hline Instant Response System & 0.111 & 2.485 & - & - & - \\
\hline
\end{tabular}

TABLE 11. HYPOTHESIS TESTING RESULTS

\begin{tabular}{|c|c|c|}
\hline H11 & Effective Learning Environment has a significant effect on Learning Motivation - X & \multirow{2}{*}{ Supported } \\
\hline H12 & Effective Learning Environment has a significant effect on Learning Engagement - Y1 & \\
\hline H13 & Effective Learning Environment has a significant effect on Learning Attitudes - Y2 & Not Supported \\
\hline
\end{tabular}

Mehran University Research Journal of Engineering \& Technology, Volume 38, No. 3, July, 2019 [p-ISSN: 0254-7821, e-ISSN: 2413-7219] 


\section{CONCLUSION}

This research study develops and empirically validates a conceptual framework that addresses the core issue of knowledge transfer through latest methodology. As such this study incorporates five variables through extensive gap analysis of research and formulates a framework, which relates these variables with effective learning environment. The aspect of technology and strategy are taken in stride during the formulation. The issue of unconventional learning methodologies is taken as a moderator and the framework presents with a novel approach to address the impact of flipped methodology of imparting education and knowledge.

As seen from the analysis results the Moderator has significantly increased the effect of all independent variables towards the dependent variable. This conclusion depicts the importance and implementation requirements for assuring that seemingly un-conventional teaching methods when combined with flipped methodology can generate an effective learning environment for classrooms of the future. The use of education technology as an enabler to enhance learning activities helps in transforming the educational environment from traditional lecture driven approach to more un-conventional discussion oriented approach. This research concludes that as we add more technology to the education stem and to the classrooms we enable more room to experiment with the knowledge base for the students. More opportunities can arise when latest technologies can be used in the educational delivery and retention system. The advent of big data analytics has greatly increased the reach of any student beyond the local resources. This global reach should be made part of the active learning sequence for the students.

One of the key conclusions of this research is the finding that the student question generation and its on-time resolution creates an effective and conducive learning environment. The questions asked by the students are the depiction of their interest in the content being delivered. Moreover, it is also important that the question depositary be kept in a database so that the response of the students can be gauged and progressive learning of the students takes place.

The research also concludes that the speed of response for a given examination or a discussion topic greatly enhances the productivity of a classroom. The effective learning environment is generated when a particular query is answered and the teacher in that class can actively generate an overall consensus about that query. The instant response system in classrooms of today can be enhanced through the use of technology. The immediate response is more so required in a virtual classroom. In today's world more classrooms are turning virtual and the students from all over the world join a particulate discussion panel. In this situation instant response system can greatly create an educational environment best suited for effective learning.

\section{RECOMMENDATIONS}

(i) Other variables and moderators can be added to the study.

(ii) Longitudinal studies may be conducted building upon the proposed framework.

(iii) Other stakeholders like faculty, institutions may be involved in the Flipped approach TEL Framework.

(iv) The proposed framework may be tested and validated in other countries with different Moderation effect

\section{ACKNOWLEDGEMENT}

Authors are thankful to the National University of Sciences \& Technology, Islamabad, Pakistan, for providing necessary facilities to complete this study.

Mehran University Research Journal of Engineering \& Technology, Volume 38, No. 3, July, 2019 [p-ISSN: 0254-7821, e-ISSN: 2413-7219] 


\section{REFERENCES}

[1] Michael, F., "Technology Enhanced Learning and Higher Education”, Oxford Review of Economic Policy, Volume 32, No. 4, pp. 632-645 [DOI: 10.1093/oxrep/ grw028], UK, 2016.

[2] Bishop, J.L., and Verleger, M.A., "The Flipped Classroom", 120th ASEE Annual Conference \& Exposition, Atlanta, Georgia, June 14-16, 2013.

[3] Mazur, E., "Peer Instruction, a User’s Manual Series", Prentice Hall, Inc, Volume 1, pp. 21-45, USA, 1997.

[4] Sohrabi, B., andIraj. H., "Implementing Flipped Classroom Using Digital Media, a Comparison of Two Demographically Different Groups Perceptions", Computers in Human Behavior, Volume, 36, No. 2, pp. 71-87. [DIO: 10.1016/j.chb.2016.02.056], Canada, 2016.

Yilmaz, R., "Exploring the Role of e-Learning Readiness on Student Satisfaction and Motivation in Flipped Classroom", Computers in Human Behavior, Volume 70, No. 3, pp. 251-260, [DIO: 10.1016/ j.chb.2016.12.085], Netherland, 2017.

Rita, V., and Asta, V., "The Need for Entrepreneurial Education at University", Journal of Teacher Education for Sustainability, Volume 20, No. 1, pp. 82-92. [DOI: 10.2478/jtes-2018-0005], Latvia, 2018.

Hwang, G.J., Lai, C.L., and Wang., "Seamless Flipped Learning, a Mobile Technology Enhanced Flipped Classroom with Effective Learning Strategies", Journal of Computers in Education, Volume 2, No. 4, pp. 449-473, [DOI: 10.1007/s40692-015-0043-0], Switzerland, 2015

[8] Song, D., Oh, E.Y., and Glazewski, K., "Student Generated Questioning Activity in Second Language Courses Using a Customized Personal Response System, a Case Study", Educational Technology Research and Development, Volume 65, No. 6, pp. 1425-1449, [DOI: 10.1007/s11423-017-9520-7], Switzerland, 2017.

[9] Simpson, V., and Oliver, M., "Electronic Voting Systems for Lectures Then and Now: A Comparison of Research and Practice", Australasian Journal of Educational Technology, Volume 23, No.2, pp.187-208, [DOI: 10.14742/ajet.1264], Australia, 2007.
[10] Han, J.H., and Finkelstein, A., "Understanding the Effects of Professors, Pedagogical Development with Clicker Assessment and Feedback Technologies and the Impact on Students Engagement and Learning in Higher Education", Computers \& Education, Volume 65, No. 2, pp. 64-76, [DOI: 10.1016/j.compedu.2013.02.002], USA, 2013.

[11] Chien, Y.T., Lee, Y.H., Li, T.Y., and Chang, C.Y., "Examining the Effects of Displaying Clicker Voting Results on High School Students Voting Behaviors, Discussion Processes, and Learning Outcomes", EURASIA Journal of Mathematics, Science and Technology Education, Volume 11, No. 5, pp. 10891104, [DOI: 10.12973/eurasia.2015.1414a], UK, 2015.

[12] Tomic, W., "Behaviorism and Cognitivism in Education", A Journal of Human Behavior, Volume 30, No. 2, pp. 34-46, USA, 1993.

[13] Amineh, J.R., and Hanieh, D.A., "Review of Constructivism and Social Constructivism", Journal of Social Sciences, Literature and Languages, Volume 1, No. 1, pp. 9-16, Georgia, 2015.

[14] Drake, J.M., and Barlow, A.T., "Assessing Students' Levels of Understanding Multiplication through Problem Writing", Teaching Children Mathematics, Volume 14, No. 5, pp. 272-277, USA, 2007.

[15] Bataineh, M., "Think-Pair-Share, Co-op-Co-op and Traditional Learning Strategies on Undergraduate Academic Performance", Journal of Educational and Social Research, Volume 5, No. 1, pp. 217, Italy, 2015.

[16] Mazur, E., "Peer Instruction: A User's Manual", Prentice Hall, Upper Saddle River, Volume 1, pp. 21-45, USA, 1997.

[17] Bloom, B.S., "Taxonomy of Educational Objectives. Handbook I: Cognitive Domain. Handbook II: Affective Domain”, David McKay, USA, 1956.

[18] Yuen, A.H.K., "Exploring Teaching Approaches in Blended Learning", International Journal of Technology Enhanced Learning, Volume 6, No. 1, pp. 3-23, UK, 2011.

[19] Joshua, R., and Matthew, K., "Context and Technological Pedagogical Content Knowledge (TPACK): A Systematic Review", Handbook of Technological Pedagogical Content Knowledge (TPCK) for Educators, Volume 47, No. 3, pp. 186-2109, [DOI: 10.1080/15391523.2015.1052663], USA, 2015. 
[20] Mubarak, M., "Factors that Influence the Adoption of E-Learning, an Empirical Study in Kuwait", Journal of School of Information Systems Computing and Mathematics Brunel University, Volume 4, No. 3, pp. 122-159, UK, 2014.

[21] Rosenblit, S., and Gros, B., "E-Learning: Confusing Terminology, Research Gaps and Inherent Challenges", Journal of Distance Education, Volume 25, No. 1, pp. 67-92, Canada, 2011.

[22] Walker, R., Voce, J., and Ahmed, J., "Survey of Technology Enhanced Learning for Higher Education in the UK, Oxford", Universities and Colleges Information Systems Handover Version Association. Volume 10, No. 2, pp. 23-57, UK, 2012.

[23] Kirkwood, A., and Price, L., "Technology Enhanced Learning and Teaching in Higher Education, What is Enhanced and How do We Know, A Critical Literature Review", Learning Media and Technology, Volume 39, No. 1, pp. 6-36, UK, 2014.

[24] Strayer, J.F., "How Learning in an Inverted Classroom Influences Cooperation, Innovation and Task Orientation", Learning Environments Research, Volume 15, No. 2, pp. 171-193, [DOI: 10.1007/s10984012-9108-4], Netherlands, 2012.

[25] McFarland, J., Hussar, B., and de Brey, C., "The Condition of Education 2017", US Department of Education, National Center for Education Statistics, No. 144, pp. 75-78, USA, 2017.

[26] Govindasamy, T., "Successful Implementation of ELearning Pedagogical Considerations", Internet and Higher Education, Volume 4, No. 3, pp. 287-299, Hong Kong, 2002.

[27] Anderson, T., and Dron, J., "Learning Technology through Three Generations of Technology Enhanced Distance Education Pedagogy", European Journal of Open, Distance and E-Learning, Volume 8, No. 3, pp. 98-19, UK, 2011.

[28] Neal, M., "Engaging Students through Effective Questions”, Journal of Education Canada, Volume 51, No. 1, pp. 23-45, Canada, 2012.

[29] Huang, K.H., Hung, K.C., and Cheng, C., "Enhancing Interactivity in Geography Class, Fostering Critical Thinking Skills through Technology", Problems of Education in the 21 st Century, Volume 50, No. 1, pp. 32-45, Hong Kong, 2012.
[30] Abreu, B., "Changing Technology, Empowering Students through Media Literacy Education”, New Horizons in Education, Volume 58, No. 3, pp. 26-33, Turkey, 2010 .

[31] Underwood, D., Banyard, E., and Davies, N., "Students in Digital Worlds, Lost in Sin City or Reaching Treasure Island", BJEP Monograph Digital Technologies, Volume 83, No. 99, pp. 83-99, UK, 2007.

[32] Chien, Y.T., and Chang, C., "Supporting Socio Scientific Argumentation in the Classroom through Automatic Group Formation Based on Students Real Time Responses", Science Education in East Asia, Volume 5, No. 3, pp. 549-563, [DOI: 10.1007/978-3-319-163901_22], Taiwan, 2015.

[33] Niemz, K., Griffiths, M., and Banyard, P., "Prevalence of Pathological Internet use among University Students and Correlations with Self-esteem", Cyber Psychologyand Behavior, Volume 8, No. 6, pp. 562-570, USA, 2005.

[34] Banyard, P., and Underwood, J., "E-Learning: The Dark Side”, E-Learning Papers, Volume 28, No. 2, pp. 34-76, USA, 2012.

[35] Joint, N., "If Google Makes You Stupid, What Should Librarians Do About It", Library Review, Volume 60, No. 4, pp. 269-278, UK, 2011.

[36] Hung, H., "Flipping the Classroom for English Language Learners to Foster Active Learning", Computer Assisted Language Learning, Volume 28, No. 1, pp. 81-96, [DOI: 10.1080/09588221.2014.967701], UK, 2015.

[37] Sekaran, U., "Research Methods for Business, a Skill Building Approach", Volume 4, pp. 126-138, John Wiley and Sons Inc, USA, 2003.

[38] Saunders, M., "Research Methods for Business Students", Pearson Education Limited, Volume 3, No. 1, pp. 381-399, UK, 2011.

[39] Robson, C., "Real world Research, a Resource for Social Scientists and Practitioner Researchers", Blackwell Oxford, Volume 2, pp. 233-256, Australia, 2002.

[40] Dillman, D., "Mail and Internet Surveys, the Tailored Design Method", Volume 2, pp. 121-134, John Wiley \& Sons, Inc, USA, 2007. 